\title{
Utilization of wasted clothes materials of uniform for agricultural and greening materials
}

\author{
Megumi Sekkuden ${ }^{1}$, Toshio Yamamura ${ }^{2}$, Tatsuo Okazawa $^{3}$, Koichi Goda ${ }^{4}$ \\ and Toshihiro Okabe ${ }^{5}$ \\ ${ }^{\mathbf{1}}$ Tombow Co.,Ltd. 2-33-1 Kameido Koto-ku Tokyo 700-0985 Japan \\ Tel: +81-3-5626-2264 Fax: +81-3-5626-2269 E-mail : megumi.sekkuden@tombow-net.co.jp \\ ${ }^{2}$ Yamamura Professional Engineering Office 18-5-702 Oimatsucho Nishinomiya Hyogo 662-0085 Japan \\ ${ }^{3}$ Yamaguchi University 2-16-1 Tokiwadai Ube Yamaguchi 755-8611 Japan \\ ${ }^{4}$ Tokyo Metropolitan Agriculture and Foresty Research Center 3-8-1 Fujimicho Tachikawa Tokyo 190-0013 Japan \\ ${ }^{5}$ Aomori Prefecture Industrial Technology Research Center 221-10 Yamaguchi Nogi Aomori 030-0142 Japan
}

We have developed the ways to utilize a large amount of abandoned uniform materials. We found out that through the PVA soaking process, uniform materials are strengthened and get the new functions, such as water permeability, moisture absorption and durability against ultraviolet rays. These are the suitable functions of materials for agriculture and for the garden greening, and it is possible to divert it to the multi sheet for agriculture, because of its durability. Moreover, by making use of scrapped materials, we have devised the flower mat which is light, easy to handle

Key words: Uniform, PVA, Agriculture, Greening, Environment

\section{INTRODUCTION}

The present state of fiber recycling which is delayed. The approach of the fiber recycling is remarkably delayed, though the resource collection advances on the citizen level, and the amount of the collection of used clothing increases. The mass of the used clothing collected under the leadership of retail stores is disposed in the incinerator.

According to the general investigation for recycling of fiber products, done by the then Ministry of International Trade and Industry in 1996 fiscal year, the total amount of abandoned fiber products is about $1,700,000$ tons (that of clothing is $1,050,000$ tons), the amount of the fiber products which is collected for recycling has remained about 180,000 tons.

This 180,000 tons is recycled as (1) old clothes 46,000 tons (2) recycled fiber rug 37,000 tons (3) waste pieces 55,000 tons. Though collected with great pains, the rate of recycled fiber materials is extremely low.

It is pointed out that the difficulty in technological development for the recycling of fiber products comes from the diversity of multiple mixture of the fiber materials, because it is necessary to pursue the feel of clothes and the sense of fashion.

Next, I want to introduce the actual circumstances of the uniform industry. The uniform material can be scrapped as clothe materials before it is sewed.

It is likely to be disposed at each stage of the company and the manufacturer. The quality of uniform material, different from the general clothes material, is severely controlled, so even little color blurs will be regarded as defect. In addition, the delivery date should be severely observed so the extra material should be prepared in the expectation that a large amount of products should be delivered at the same time. If the design of the uniform is changed by the reason of customers, these extra materials will be scrapped. Unnecessary clothe materials cannot be diverted to other use to keep the security of the enterprises or the schools. These rolls must be scrapped by the basic rule.

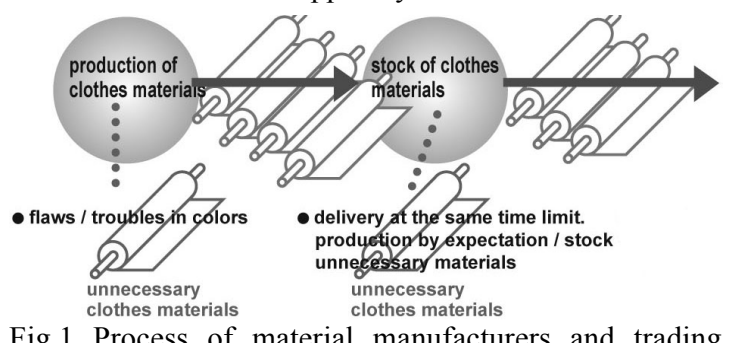

Fig.1 Process of material manufacturers and trading companies

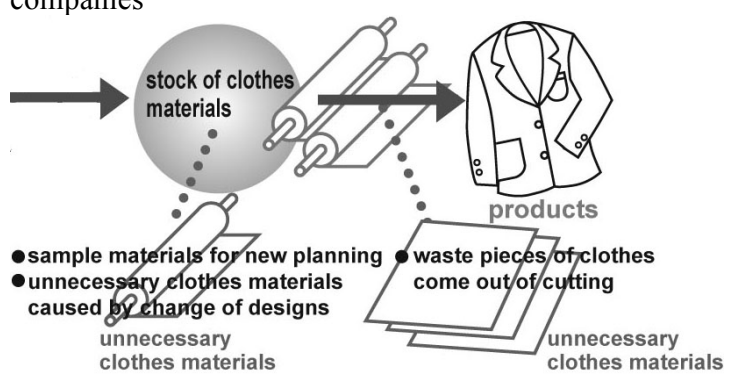

Fig.2 Process of uniform manufacturers

\section{EXPERIMENTAL METHODS}

\subsection{FEATURES OF THE UNIFORM MATERIALS}

In the uniform material used for an overdress and heavy clothes (jacket, pants, and skirt) of the uniform of the enterprise and the school, a wool polyester mixed material is a main current. As for the uniform, a high endurance performance is required. i.e. it should endure to be worn three years or more. Therefore, it is thick, 
twine of the string is strong, and it is a feature that the solidity degree is high, and strong in the material compared with general clothes. Moreover, it is dyed in deep colors, and the color is a material which does not fade easily.

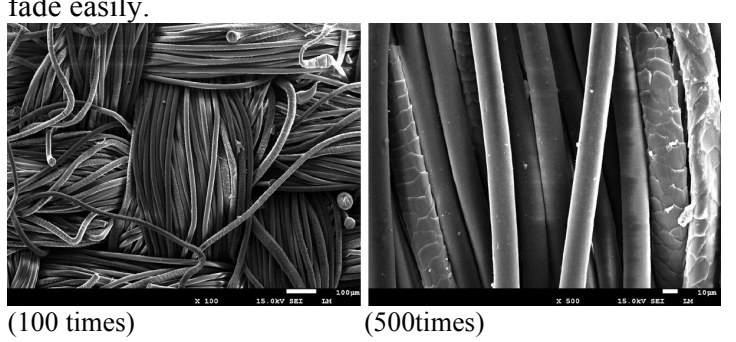

Fig.3 Polyester mixture SEM Photograph

Uniform manufacturer, such as Tombow( Inc.), where I am working, adopts only the uniform materials that satisfy the JIS standards. i.e., uniform material has the quality of stability and durability, and can be used long. So when it is scrapped, large amount of waste will be generated. Tombow(Inc.) abandoned about seven tons of the uniform material in 2009 , according to this rule. It is estimated that in the entire school uniform industries, about 50 tons or less of the uniform material is scrapped in a year without being commercialized.

It is important to design the method of reproducing an extremely excellent uniform material as a recycling material in the uniform industry, when thinking about such a situation.

We have tried to find out the way how to decrease the amount of abandonment of the uniform material and how to recycle it by making the best use of the feature of the disposed uniform material, with the restriction that the security of customer is the top priority. And we researched on the various method, with a variety of trial and error.

\subsection{RESEARCH ON DIVERSION OF THE MATERIALS TO AGRICULTURE AND GARDENING}

The author thought whether it is possible to recycle the material by adding a new feature while making the best use of the solidity of the uniform material. Along this line, and following the guidance and advice of the co investigators, the author tried making compound by processing to soak the uniform materials into the PVA solution.

As a result, we have found out that the some functions are added to the material, such as water-moisture absorption, moisture permeability, heat retentivity, and durability (chiefly against ultraviolet rays), etc. These functions are suitable for materials for agriculture and for the gardening and greening.

The heavy clothes uniform material (mixture of wool and polyester) without processing cannot be used long for agriculture, because the wool of natural fiber will corrode in a comparatively short term. However, we have found out that the PVA soaking process make the material suitable for agriculture and garden-greening, and found out the possibility of new use.

This is quite a new method of recycling the fiber materials that has not been included in the former way of recycling.
The concrete method is described later.

\subsection{PVA (poly Vinyl Alcohol)}

PVA (poly Vinyl Alcohol) is a kind of synthetic resin, i.e. the biodegradable resin of a typical aqueous synthetic polymer with very strong hydrophilicity, which has a lot of hydroxyl group(-OH) in the molecule. PVA used this time is 117 Pobarl made by Kuraray Co., Ltd. polymerization level 1700.

Because the polymerization level and the saponification level can be easily adjusted, various characteristics can be obtained. [1]

Safety for plants and animals of PVA is very high. Moreover, there is biodegradability in PVA of the low polymerization level, and it is listed in green-pra-positive-list. Because the process of biodegradation progresses very slowly, the compound of high polymerization level has durability.

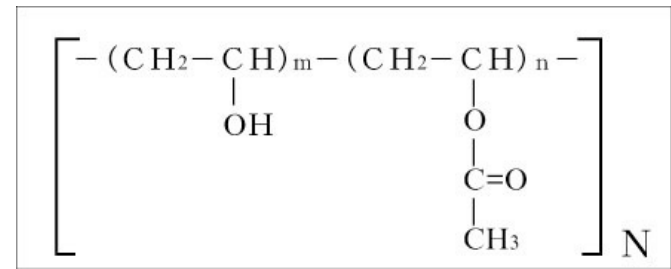

Fig.4 Chemical formula of PVA ( Poly Vinyl Alcohol) $\mathrm{N}=$ Polymerization level $\mathrm{n}$ : Degree of saponification

\section{RESULTS AND DISCUSSION \\ 3.1 IMPROVEMENT OF PERFORMANCE BY COMPOUNT}

To confirm the difference of the characteristic of the polyester wool mixture material for uniform and the PVA soaking processed material, the tension test was done. The polymerization level of PVA used here, is 1700 and the density of the solution is $9 \%$.

Outline of examination:

The test piece was cut out to $50 \mathrm{~mm}$ in the total length and $15 \mathrm{~mm}$ in width along the fiber.

The size of the test piece was assumed to be $10 \mathrm{~mm}$ in the grip part, and $30 \mathrm{~mm}$ the gauge length.

The tension test was made in $<$ pull $>$ speed $3.0 \mathrm{~mm} / \mathrm{min}$ by using the tension compression examination machine (capacity $1.0 \mathrm{kt}$ made by the JT Torshi company). The result is shown as follows.

Table.1 Result of tensile test in polyester mixture and polyester mixture with PVA

\begin{tabular}{|c|c|c|}
\hline Sample number & $\begin{array}{c}\text { Polyester mixture } \\
(\mathrm{N} / \mathrm{g})\end{array}$ & $\begin{array}{c}\text { Polyester mixture } \\
\text { With PVA(N/g) }\end{array}$ \\
\hline 1 & 398 & 612 \\
\hline 2 & 428 & 590 \\
\hline Average & 413 & 601 \\
\hline
\end{tabular}

Load - hour line chart, comparing polyester wool mixture material and PVA soaking processed material (Load - hour line chart: 100sec section corresponds to warp 0.167 because the pull speed is $30 \mathrm{~mm} / \mathrm{min}$ and the gauge length is $30 \mathrm{~mm}$.) 


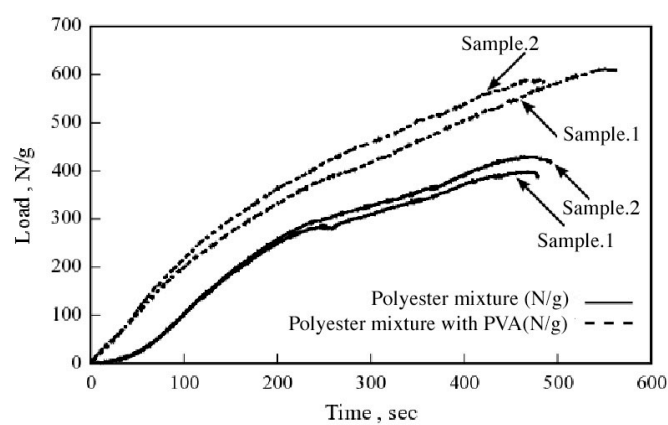

Fig. 5 Tensile test of polyester mixture and polyester mixture with PVA

Figure 5 of the line chart of the hour (expansion) shows that the breaking weight of PVA soaking processed material is obviously 1.5 times higher in average than that of the polyester wool mixture material. The former is combined by PVA inclusion and soaking. It changes from the first stage of standing up in a linear form. On the other hand, the latter polyester wool mixture material stands up behaving in non-linear form peculiar to a usual cloth material.

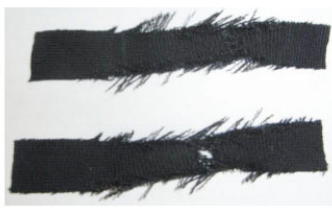

(a) Polyester mixture cloth
(b)Polyester mixture cloth with PVA

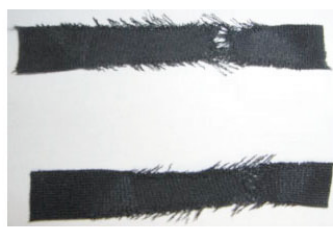

Fig. 6 Tensile test

The breaking aspect is similar as shown by (a) (b) of Figure 6. However, the polyester wool mixture material is constricted at the early stage, and is broken in a part near the center of the test piece at the initial stage of transforming. On the other hand, the PVA soaking processed material was broken at the part close to the grip, because the cloth was gripped directly. If the tab etc. are bonded and the test piece is made, the weight will be increased further to break the test piece.

\subsection{DIVERSION TO MULTI SHEET FOR AGRICULTURE}

First of all, we have made the PVA soaking process to the unnecessary cloth materials of the long scale (mainly, 150 centimeters in width and at most 50 meters in length), and tried the diversion to the multi sheet for agriculture. We used it as a multi sheet for anti-weed screen for the perennial trees in the blueberry orchard.

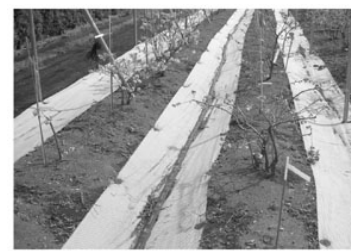

(a) 2009.4 .16

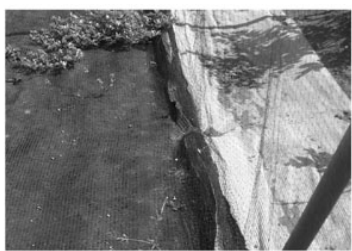

(b)2009.7.16
Fig.7 Example of executing multi sheet

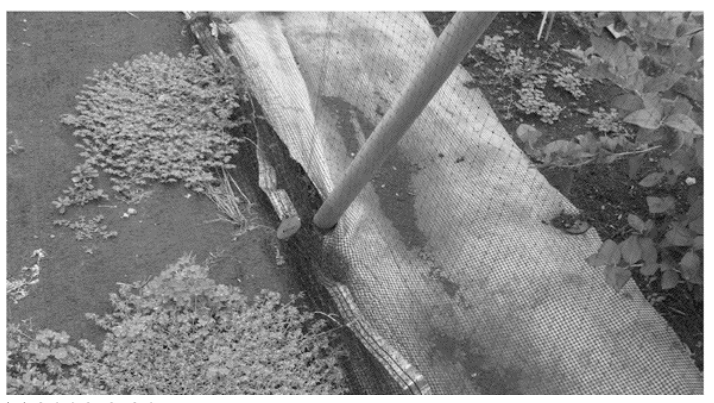

(c)2009.9.20

Fig.7 Example of executing multi sheet

As a former multi sheet (polyethylene material) was woven rough to get moisture absorption and moisture permeability, the weeds can grow out of mesh.. But the material of PVA processed multi-sheet passes water promptly, so the weeds do not grow easily, and is expected to be lasting and usable for more than five years. It can be said that this diversion method make the best use of durability of the uniform material.

In addition, by making the best use of the excellent functions of PVA material, i.e. moisture absorption and moisture permeability, we examined to use it as a covering material for the garlic cultivation in the cold district. The former polyethylene sheet is not porous, so it sweats. As a result, the roots of the seedling are hurt, and growth is disturbed. On the other hand, as PVA processed multi-sheet is excellent in absorption and permeability of moisture, so it does not sweat. It is extremely effective for the seedling promotion in the cold district. [2]

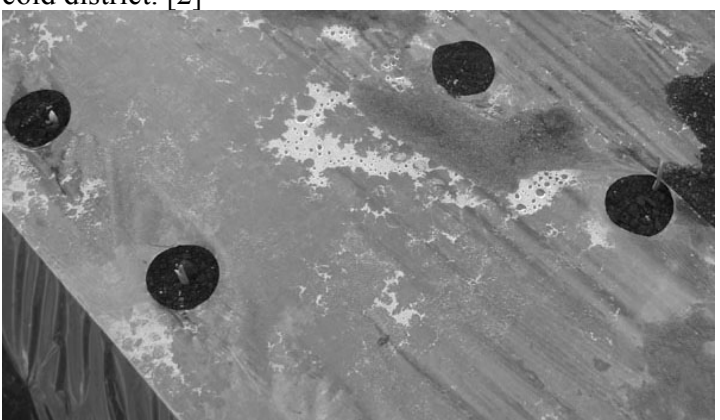

Fig.8 Polyethylene multi-sheet in garlic field (2010.11)

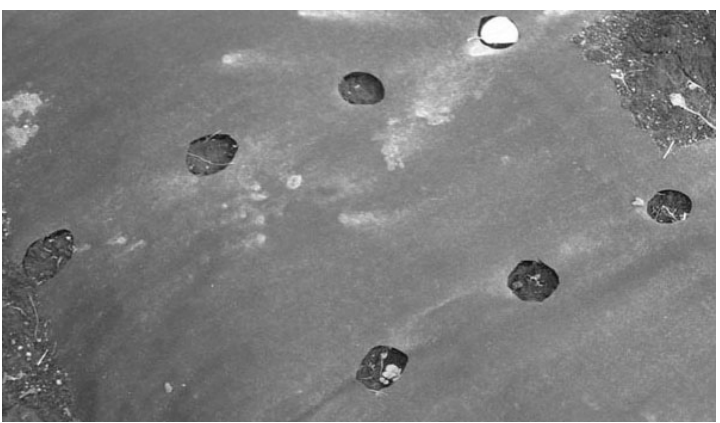

Fig.9 PVA multi-sheet in garlic field (2010.11)

We examined it also as a shading sheet for such as white spring onions in the house.

It has been proved that the PVA processed multi-sheet does not sweat, and it has an effect of preventing the bacillus to spread and the rate of defective farm products 
falls. Moreover, it works as the shading sheet, so there is no need to heap up the soil and the work can be reduced greatly.

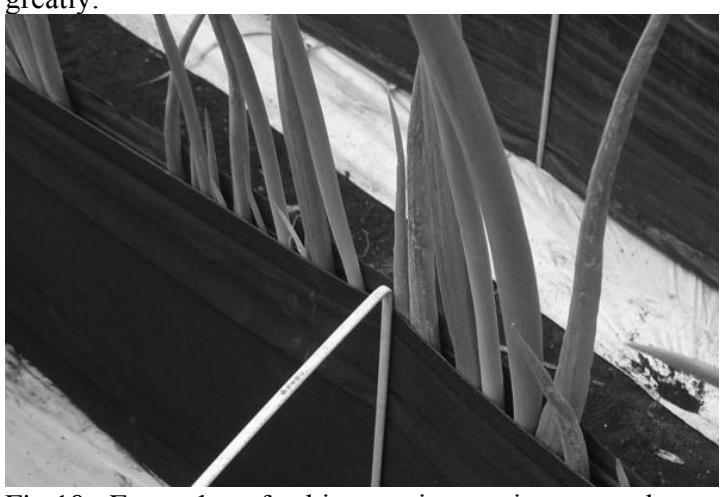

Fig.10 Example of shiro spring onion greenhouse cultivation by PVA multi-sheet for shading(2010.11)

\subsection{DIVERSION TO FLOWER MAT FOR GARDENING}

As mentioned above, long cloth material is used to make the multi sheets for agriculture. How about the waste pieces which are generated in large amounts at the stages of production of uniform. We devised the portable flower mat for the wall greening by plant cultivation to utilize the waste pieces of cloth material (the utility model No.3157340). This flower mat can be made of remains of clothes even about one meter in width.

The soil in the mat does not spill easily even if it is upset because of the special structure of it. The surface sheet of the mat is doubled and each sheet is slit crosswise and made the opening free to open and close. By using the lightened vegetable soil and so on, we can produce the plant cultivation mat for wall greening which is lasting and suitable for growth of plant.
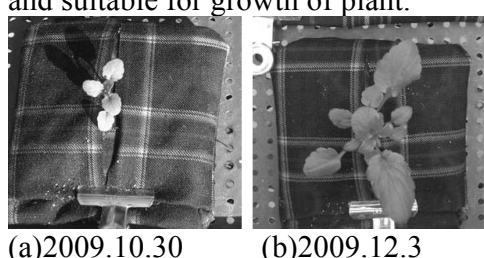

(b) 2009.12 .3

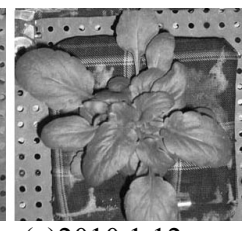

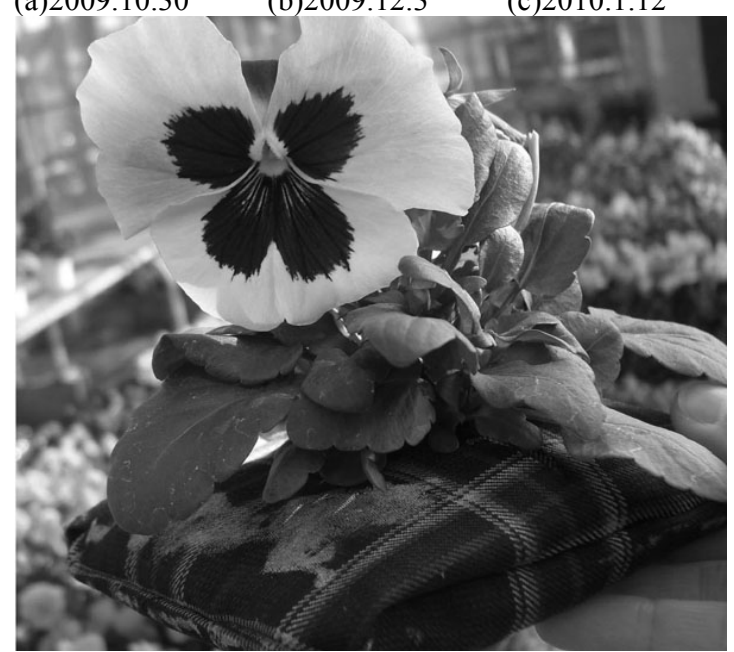

(d)2010.2.18

Fig.11 Example of using as plant cultivation mat
Different from potteries and plastic vessels used for the plant cultivation etc. the processing of the fiber material is extremely easy. For instance, if it is shaped like a bag and a string is applied to it, it easily becomes a flower pot for the wall greening.

There is a great possibility to use it as a teaching material for school by refining the design and making variety of type of mat in the future.

\section{CONCLUSION}

(1)Use as multi sheet for high-value-added agriculture Because it has durability as a multi sheet for agriculture and it can be used for a long term, the great amounts of abandoned or incinerated polyethylene sheet can be reduced, and the farm work in the farming site can be reduced. In addition, if we can make the best use of the excellent PVA function, it will be possible to develop new methods of cultivation. [3]

(2)Creation of a new style of appreciation of floriculture and a new use for gardening/greening materials

The flower mat used indoors is relatively small, so we can enjoy growing flower on the flower mat at hand in the room. By making the best use of the feature that it is possible to appreciate easier than potted plant, longer period than cut flowers, I want to create the new appreciation style of new floriculture in the living environment without the garden or without space to decorate with flowers and I want to create a new demand for floriculture.

(3)It seems that there is a great potential demand for the multi sheet for agriculture for the farm products with a high additional value, so I want to advance the actual research on that. Moreover, the important thing for the flower mat used indoors is, not only utility, handiness to treat, but also the beauty of design. I plan to combine it with the light soil which can be incinerated and biomass anti-bacterial oil, and aim to complete the package commodity.

\section{REFERENCE}

[1] ToshioYamamura, JTCC Information ,5(2010).

[2]Taizo Igarashi,Mami Kinoshita,Yoshiyuki

Suzuki,Ayako Yoshida and Yoshiaki kamichi, Journal of Agricultual Meteorology, 65(1), 61-67 (2009).

[3]Akira Hoshino, Plastics, 46(1), 130-133(1995).

(Received July 4, 2011; Accepted November 6, 2011) 